\title{
Structure of a factor VIII C2 domain-immunoglobulin G4к Fab complex: identification of an inhibitory antibody epitope on the surface of factor VIII
}

Paul Clint Spiegel Jr, Marc Jacquemin, Jean-Marie R. Saint-Remy, Barry L. Stoddard, and Kathleen P. Pratt

The development of an immune response
to infused factor VIII is a complication
affecting many patients with hemophilia
A. Inhibitor antibodies bind to antigenic
determinants on the factor VIII molecule
and block its procoagulant activity. A
patient-derived inhibitory immunoglobu-
lin G4k antibody (BO2C11) produced by
an immortalized memory B-lymphocyte

cell line interferes with the binding of factor VIII to phospholipid surfaces and to von Willebrand factor. The structure of a Fab fragment derived from this antibody complexed with the factor VIII C2 domain was determined at $2.0 \AA \AA$ resolution. The Fab interacts with solventexposed basic and hydrophobic side chains that form a membrane-association surface of factor VIII. This atomic resolution structure suggests a variety of amino acid substitutions in the $\mathbf{C} 2$ domain of factor VIII that might prevent the binding of anti-C2 inhibitor antibodies without significantly compromising the procoagulant functions of factor VIII. (Blood. 2001;98:13-19)

(๑) 2001 by The American Society of Hematology

\section{Introduction}

Factor VIII is a large, 2332-residue plasma glycoprotein that acts as a regulatory cofactor in the process of blood coagulation. ${ }^{1-3}$ It binds to activated factor IX (factor IXa) in the presence of calcium and negatively charged phospholipids that are presented at the surface of activated platelets to form a membrane-associated, proteolytically active complex. Upon complex formation, the $\mathrm{V}_{\max }$ (maximum velocity) of factor IXa is increased by approximately 200000 -fold, promoting the rapid activation of its substrate, the serine protease factor $\mathrm{X}$. The proteolytic conversion of factor $\mathrm{X}$ to its active form, $\mathrm{Xa}$, is a central control point in the coagulation cascade, leading to activation of thrombin, formation of a fibrin mesh, and establishment of a stable blood clot. The binding of factor VIIIIa and other activated proteins to these membrane surfaces allows for localization of procoagulant processes to sites of vascular damage.

The factor VIII sequence contains 6 sequential domains arranged in the order A1-A2-B-A3-C1-C2. ${ }^{4-6}$ The A domains are homologous to one another and display sequence similarity to the copper-binding protein ceruloplasmin. They are flanked by short spacer sequences that are highly acidic. The $\mathrm{C}$ domains are also homologous to each other and have a weak homology to the discoidin protein fold family (eg, the lipid-binding domain of galactose oxidase). ${ }^{7,8}$ The circulating form of the factor VIII protein is a metal bridged heterodimer consisting of a heavy chain (A1-A2-B) and a light chain (A3-C1-C2). This form of factor VIII is bound tightly to von Willebrand factor (vWF). Factor VIII is processed further by specific thrombin cleavages into a heterotrimeric form. This active form, factor VIIIa, dissociates from vWF and binds to negatively charged phospholipids on activated platelet surfaces. The carboxyl terminal C2 domain of factor VIII contains binding sites for vWF and for negatively charged phospholipids. The binding of factor VIIIa to membranes involves stereoselection for $O$-phospho-L-serine, the negatively charged head

From the Graduate Program in Biomolecular Structure and Design, University of Washington, and Division of Basic Sciences, Fred Hutchinson Cancer Research Center, Seattle, WA; and Center for Molecular and Vascular Biology, Katholieke Universiteit Leuven, Campus Gasthuisberg, Leuven, Belgium.

Submitted December 19, 2000; accepted March 6, 2001.

Reprints: Barry L. Stoddard, Fred Hutchinson Cancer Research Center, group of phosphatidylserine (PS)..$^{9}$ The binding of factor VIII or VIIIa to vWF or PS is mutually exclusive, even though the activation of factor VIII involves cleavages outside the $\mathrm{C} 2$ domain. This implies that the binding sites for vWF and PS overlap on the C2-domain surface.

Hemophilia A is a congenital bleeding disorder that is due to deleterious factor VIII gene mutations. These mutations may block factor VIII expression or secretion and may involve premature truncations, sequence rearrangements, or single-residue substitutions. To date, a total of 28 missense mutations at 21 different amino acids within the $\mathrm{C} 2$ domain have been associated with hemophilia A. ${ }^{10}$ The crystal structure of the factor VIII C2 domain was reported recently. ${ }^{11} \mathrm{~A}$ mechanism for the interaction of factor VIII with negatively charged phospholipid surfaces, as well as explanations for the molecular basis of hemophilia A point mutations localized to this domain, were proposed on the basis of this study. ${ }^{10,11}$

Current therapy for patients with hemophilia A involves therapeutic infusions of factor VIII. Inhibitory antibodies against factor VIII, which may occur transiently or may persist as a serious long-term complication, are generated in up to $35 \%$ of patients with severe hemophilia A. ${ }^{12-16}$ These patients generally have very low or undetectable factor VIII antigen. Patients who have mild or moderate hemophilia A, which is usually associated with missense mutations, can also develop inhibitory antibodies. This is less common and occurs in $3 \%$ to $13 \%$ of patients. ${ }^{17,18}$ Antibody inhibitor development has been associated with the mutations R593C and W2229C (single-letter amino acid code), with about a $40 \%$ inhibitor incidence for each mutation. Autoantibodies to factor VIII can also develop in postpartum women or in individuals with various underlying disease states, but this is very rare, as it occurs in one per million individuals. ${ }^{19,20}$

Division of Basic Sciences, 1100 Fairview Ave North A3-023, Seattle, WA 98109; e-mail: bstoddar@fhcrc.org.

The publication costs of this article were defrayed in part by page charge payment. Therefore, and solely to indicate this fact, this article is hereby marked "advertisement" in accordance with 18 U.S.C. section 1734.

(C) 2001 by The American Society of Hematology 
The primary antigenic epitopes on factor VIII have been localized to the $\mathrm{A} 2$ and $\mathrm{C} 2$ domains. ${ }^{21-26}$ The $\mathrm{A} 3$ and $\mathrm{C} 1$ domains and the acidic region between $\mathrm{A} 1$ and $\mathrm{A} 2$ have also been implicated, although epitopes in these regions occur less frequently. ${ }^{27,28}$ Inhibitory antibodies against the A2 domain generally allow factor VIII to form complexes with vWF or factor IXa, but the proteolytic activation of factor $\mathrm{X}$ is blocked. ${ }^{13}$ In contrast, inhibitory antibodies specific to the $\mathrm{C} 2$ domain have been shown to prevent the binding of factor VIII to vWF and to membrane surfaces that expose PS. Two studies have localized a C2-domain epitope to the regions between residues 2181 to $2243^{22}$ and 2248 to $2312 .{ }^{22,29}$ Blocking the interaction between factor VIII and vWF greatly reduces the half-life of factor VIII in the circulation, while antibodies that prevent the binding of factor VIIIa to membrane surfaces abolish its procoagulant cofactor function.

To gain further insight into the interaction of autoantibodies and alloantibodies against factor VIII at the molecular level, a factor VIII-specific human IgG4 $\mathrm{\kappa}$ antibody (BO2C11) was produced by a cell line derived from the memory B-cell repertoire of a patient with hemophilia A with a strong inhibitor response. ${ }^{30}$ Biosensor measurements indicated that although the association rate of factor VIII with $\mathrm{BO} 2 \mathrm{C} 11$ is slower than that measured for factor VIII binding to $\mathrm{VWF}$, the dissociation rate of the factor VIII:BO2C11 complex is 100-fold slower than that of the factor VIII:vWF complex. ${ }^{30}$ Thus, the current working model for the inactivation of factor VIII by $\mathrm{BO} 2 \mathrm{C} 11$ is that the antibody forms a tight, stable complex with factor VIII (or factor VIIIa) as it dissociates from vWF. The antibody blocks the C2-domain membrane-binding site, thus effectively sequestering factor VIII and neutralizing its procoagulant effects. The antibody complex may also lead to accelerated clearance of the bound factor VIII, but this has not been measured directly.

\section{Materials and methods}

The recombinant $\mathrm{C} 2$ domain was expressed and purified as described previously. ${ }^{11}$ The factor VIII C2-domain-specific human IgG4 $\mathrm{\kappa}$ monoclonal antibody (BO2C11) was digested with papain, and the Fab fragment was purified using standard methods. Approximately equimolar amounts of Fab and $\mathrm{C} 2$ protein were combined in $10 \mathrm{mM}$ HEPES, $0.1 \mathrm{M} \mathrm{NaCl}$, $\mathrm{pH} 7.5$, at approximately $10 \mathrm{mg} / \mathrm{mL}$ total protein concentration. Crystals were grown at room temperature in 16\% polyethylene glycol (PEG) 8000, $0.1 \mathrm{M}$ HEPES ( $\mathrm{pH}$ 7.0), $0.2 \mathrm{M} \mathrm{NaCl}$. The crystals were flash frozen in the same solution, plus a final concentration of $25 \%$ vol/vol PEG 400 as cryoprotectant. Data were collected to $2.0 \AA$ resolution at the Advanced Light Source (Berkeley, CA) beamline 5.0.2 and processed using Denzo/ Scalepack program suite. ${ }^{31}$ The space group was $\mathrm{P} 22_{1} 2_{1} 2_{1}$ with unit cell parameters $a=64.5 \AA, b=73.7 \AA$, and $c=112.4 \AA$. The structure was solved by molecular replacement with the use of EPMR version 2.1.32 The models used for molecular replacement during independent, iterative searches were the recombinant factor VIII C2 domain, ${ }^{11}$ the constant domain of a human IgG4 $\mathrm{k}$ Fab (pdb acc.: 1BBJ), and a molecular model of the variable domain that used optimal CDR loop length and sequence alignment (pdb: 1GC1 and 1AD9). The constant-domain search model was found by searching the Protein Data Bank for a structure of a Fab of homologous classification. The heavy and light variable-chain sequences were used independently to locate optimal search models, and the program Blast (Basic local alignment search tool) was used to search the Protein Data Bank (the $V_{L}$ and $V_{H}$ sequences are in the European Molecular Biology Laboratory (EMBL) Nucleotide Sequence Database under the accession numbers AJ224084 and AJ224083, respectively). As each phase solution was determined, it was fixed in orientation as subsequent rounds were performed. Model building of all deleted loops and side chains was performed with XFIT ${ }^{33}$ version 3.7, and the structure was refined using $\mathrm{CNS}^{34}$ after removing $10 \%$ of the data for cross-validation purposes. The final model consists of 564 amino acids and 477 water molecules. The $\mathrm{R}_{\text {cryst }}$ and $\mathrm{R}_{\text {free }}$ both decreased at every step of the refinement, and the final $\mathrm{R}_{\text {cryst }}$ was $20.4 \%$ and $R_{\text {free }}$ was $25.5 \%$. The stereochemical validity of the final model was verified using Procheck. ${ }^{35}$ Data and refinement statistics are shown in Table 1.

\section{Results}

The structure of the C2-domain-BO2C11 Fab complex was solved to $2.0 \AA$ A resolution (Table 1). The factor VIII C2-domain construct consists of residues 2171 to 2332 . The heavy and light chains of the Fab fragment consist of residues 1 to 211 and 1 to 212 , respectively. Electron density of the entire complex was of excellent quality except for 3 residues at the $\mathrm{C} 2$-domain amino and carboxyl termini, 4 residues in the light chain, and 13 residues in the heavy chain. None of these residues was involved in the binding interface. The crystallographic model contains a total of 477 water molecules, 41 of which reside in the binding region of the complex. The core structure of the $\mathrm{C} 2$ domain is completely conserved, displaying an 8 -stranded $\beta$-sandwich fold. The amino and carboxyl terminal regions of the $\mathrm{C} 2$ domain are linked by an internal disulfide bond joining $\mathrm{C} 2174$ to $\mathrm{C} 2326$. Two exposed hydrophobic $\beta$ turns and an underlying pair of basic residues (R2215 and R2220), all previously hypothesized to participate in the C2-membrane-binding site, formed critical interactions at the antibody interface (Figures 1

Table 1. Data and refinement statistics

\begin{tabular}{|c|c|c|}
\hline Type of data & Category & Result \\
\hline \multicolumn{3}{|l|}{ Diffraction data } \\
\hline & Resolution & $2.0 \AA$ \\
\hline & Source & $\mathrm{P} 2{ }_{1} 2_{1} 2_{1}$ \\
\hline & Unit cell (a) & $64.5 \AA$ \\
\hline & (b) & $73.7 \AA$ \\
\hline & (c) & $112.4 \AA$ \\
\hline & Wavelength & $1.07 \AA$ \\
\hline & Unique reflections & 36867 \\
\hline & Redundancy & 7.7 \\
\hline & Completeness* & $99.6(98.8)$ \\
\hline & $\mathrm{R}_{\text {merge }}$ & 6.1 \\
\hline \multicolumn{3}{|l|}{ Refinement } \\
\hline & Resolution range & $50-2.0 \AA$ \\
\hline & $\mathrm{R}_{\text {cryst }}$ & $20.4 \%$ \\
\hline & $\mathrm{R}_{\text {free }}(10 \%)$ & $25.5 \%$ \\
\hline & No. of protein atoms & 4335 \\
\hline & No. of solvent atoms & 477 \\
\hline & Ramachandran dist. & $87.8,11.4$ \\
\hline & $\begin{array}{l}\text { (\% core, allowed, generously } \\
\text { allowed, disallowed) }\end{array}$ & $0.4,0.4 \dagger$ \\
\hline & rms bonds, angles & $0.0054,1.33$ \\
\hline & Average $\langle\mathrm{B}\rangle \S$ & 24.25 \\
\hline \multicolumn{3}{|l|}{$\begin{array}{l}\text { Molecular } \\
\text { replacementł }\end{array}$} \\
\hline & Model 1 (variable domain) & Correlation coefficient 0.416 \\
\hline & & $R$ value 0.733 \\
\hline & Model 2 (C2 domain) & $\begin{array}{l}\text { Correlation coefficient } 0.381 \\
R \text { value } 0.753\end{array}$ \\
\hline & Model 3 (constant domain) & $\begin{array}{l}\text { Correlation coefficient } 0.564 \\
R \text { value } 0.651\end{array}$ \\
\hline
\end{tabular}

$R_{\text {cryst }}$ indicates refinement $R$-factor; $R_{\text {free }}$, cross-validation $R$-factor on $5 \%$ of randomly selected reflections.

${ }^{*}$ Completeness is reported for all reflections and for the highest resolution shell. †Two residues (A52 and H2315) are in the disallowed region of the Ramachandran plot. Both residues have good electron density to indicate proper conformation. $\ddagger$ Values reported by EPMR version 2.1 .

$\S$ Average temperature factor of crystallographic structure. 

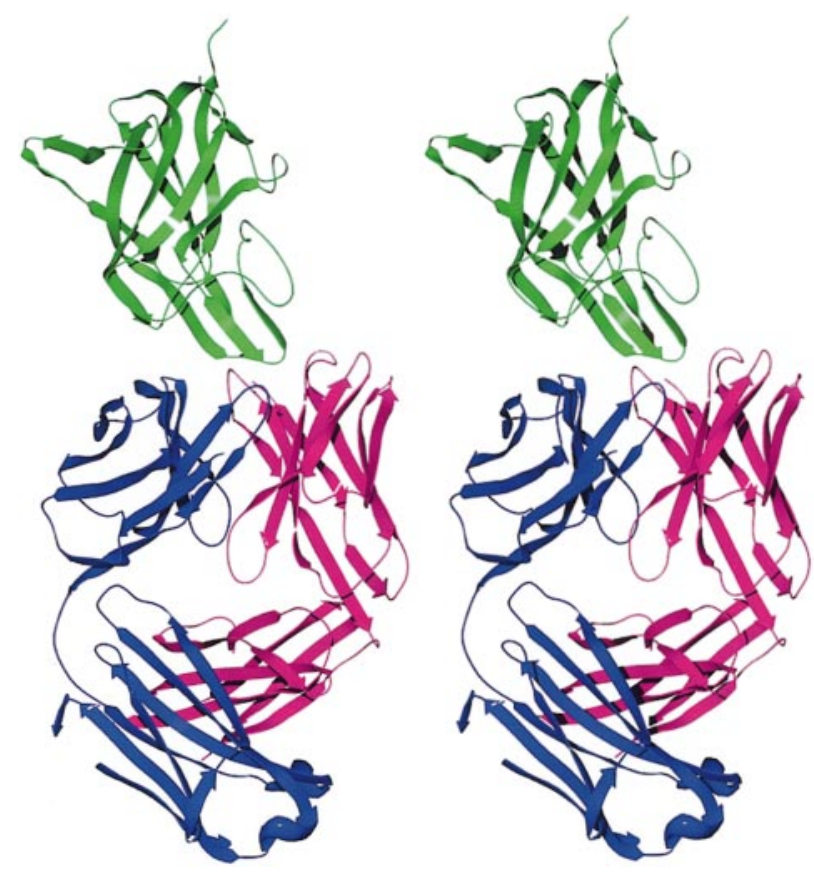

Figure 1. Stereo ribbon diagram of the factor VIII C2-domain/BO2C11 Fab complex. The light chain, heavy chain, and C2 domain are displayed in blue, magenta, and green, respectively. The $\mathrm{BO} 2 \mathrm{C} 11 \mathrm{Fab}$ displays a typical immunoglobulin fold with $18 \beta$ strands in the light chain and $19 \beta$ strands in the heavy chain. Two $\beta$ hairpins from the $\mathrm{C} 2$ domain project into the CDR loops of the Fab fragment.

and 2; Table 2). An area of approximately $1200 \AA^{2}$ on the surface of each molecule is buried in the protein interface. The C2-epitope surface is basic in character, whereas the Fab surface is quite acidic at the interface, indicating a favorable overall charge complementarity (Figure 3).

The fold of the $\mathrm{C} 2$ domain is similar in the free and Fab-bound forms, with an all-atom rms difference of $0.33 \AA$. However, there is a shift in the position of the hydrophobic $\beta$-hairpin loop containing M2199 and F2200. The backbone of this loop region twists significantly, allowing the side chains to form specific interactions at the binding interface (Figure 4). The analogous region of the factor V C2 domain has been visualized in 2 different conformations, ${ }^{36}$ indicating that the membrane-binding region has some inherent flexibility.

Epitope mapping using fragments of the factor VIII C2 domain indicated that $\mathrm{BO} 2 \mathrm{C} 11$ does not recognize a linear epitope corresponding to a single stretch of amino acid residues. ${ }^{30}$ Rather, it interacts with a conformational epitope composed of side chains from various regions within the $\mathrm{C} 2$ sequence that are adjacent to each other in the folded protein. These results are in agreement with the interactions present in this crystal structure, as illustrated in Figure 2 and listed in Table 2. Two $\beta$-turn regions (residues 2250 to 2253 and 2197 to 2203) and an additional loop containing residues Q2222 and V2223 present hydrophobic residues at the protein surface. These residues interact with residues from multiple CDRs on the heavy and light chains of the Fab and the amino terminus of the heavy chain. These loop regions of factor VIII represent the largest amount of surface area buried within the antibody interface. Two basic residues from the C2 protein, R2215 and R2220, are postulated to interact with phospholipid head groups. These residues form salt links with D52 and D102 of the heavy chain, respectively. Finally, residues H2315 and Q2316 participate in polar interactions with specific residues and buried water molecules at the antibody interface.

\section{Discussion}

The BO2C11 IgG antibody binds to the $\mathrm{C} 2$ domain of factor VIII, inhibiting its ability to bind negatively charged phospholipids and $\mathrm{vWF}^{30}$ The evidence strongly suggests that the BO2C11 antibody masks the membrane-binding surface of the $\mathrm{C} 2$ domain and thus prevents binding to negatively charged phospholipids. The membrane-binding surface of factor VIII has been proposed to consist of $2 \beta$-hairpins turns and an adjacent loop. This region displays 5 exposed hydrophobic residues that are available to participate in membrane binding (L2251, L2252, M2199, F2200, and possibly V2223). Four of these hydrophobic residues are buried in the Fab complex, whereas V2223 is located immediately adjacent to the interface and is in contact with the Fab molecule. A ring of positively charged basic residues is positioned to interact with charged phospholipid head groups upon burial of the hydrophobic side chains in the lipid bilayer. Two of these residues, R2215 and $\mathrm{R} 2220$, are buried in the Fab interface, where they form salt bridges with $\mathrm{D}$ residues in $\mathrm{BO} 2 \mathrm{C} 11$ (Figure 2).

The large contact surface between the $\mathrm{C} 2$ domain and $\mathrm{BO} 2 \mathrm{C} 11$ is in agreement with the high affinity of factor VIII binding to $\mathrm{BO} 2 \mathrm{C} 11$, as measured by surface plasmon resonance. The latter showed an antibody-factor VIII association rate constant of $7.4 \times 10^{5}$. $\mathrm{M}^{-1} \cdot \mathrm{s}^{-1}$ and dissociation rate constant of less than or equal to $1 \times 10^{-5} \cdot \mathrm{s}^{-1}$, with a calculated apparent dissociation constant of $1.4 \times 10^{-11} \cdot \mathrm{M}^{-1.30}$

Anti-factor VIII antibodies were initially distinguished according to the kinetics of factor VIII inactivation. ${ }^{37,38}$ In 1982, Gawryl and Hoyer $^{39}$ delineated 2 populations of such antibodies: type I antibodies inactivate factor VIII completely, following secondorder kinetics; whereas type II inhibitors inactivate factor VIII only partially, even when added in large excess over factor VIII, and follow more complex kinetics. Later, Biggs ${ }^{40}$ observed that even antibodies completely inactivating plasma factor VIII frequently follow complex kinetics of interaction with factor VIII, thereby identifying an intermediate category between type I and type II inhibitor antibodies. As a consequence of their particular kinetics of factor VIII inhibition, such antibodies can be difficult to quantify in plasma using the conventional Bethesda method. ${ }^{41}$

Competition with vWF for factor VIII binding was first described as the mechanism responsible for the type II kinetic pattern of many type II inhibitor antibodies, which in the absence of vWF completely inhibited factor VIII activity following secondorder kinetics, much like type I inhibitors. ${ }^{39}$ However, some type II inhibitors inactivate factor VIII only when the latter is bound to vWF, ${ }^{21,42}$ and recent observations have indicated that some type II antibodies inhibit factor VIII partially even in the absence of $\mathrm{vWF}^{27}$ The population of type II inhibitors therefore appears to be heterogeneous.

The data on the crystal structure of the $\mathrm{C} 2$ domain in combination with $\mathrm{BO} 2 \mathrm{C} 11$ presented here shed light on the actual mechanisms by which the antibody inhibits factor VIII function. BO2C11 inactivates factor VIII following a kinetic pattern intermediate between that of type I and type II inhibitors. With excess of antibody, factor VIII inactivation by $\mathrm{BO} 2 \mathrm{C} 11$ is complete. ${ }^{30}$ However, when analyzed as a function of time, the kinetics of the reaction is different from that of type I inhibitor antibodies; that is, the relation between the logarithm of residual factor VIII activity and time is not linear (M.J., unpublished results, September 1997). The likely explanation for this observation is that $\mathrm{BO} 2 \mathrm{C} 11$ is in competition with vWF for factor VIII binding. ${ }^{30}$ In plasma, factor VIII is complexed to vWF, which prevents $\mathrm{BO} 2 \mathrm{C} 11$ binding. Over 


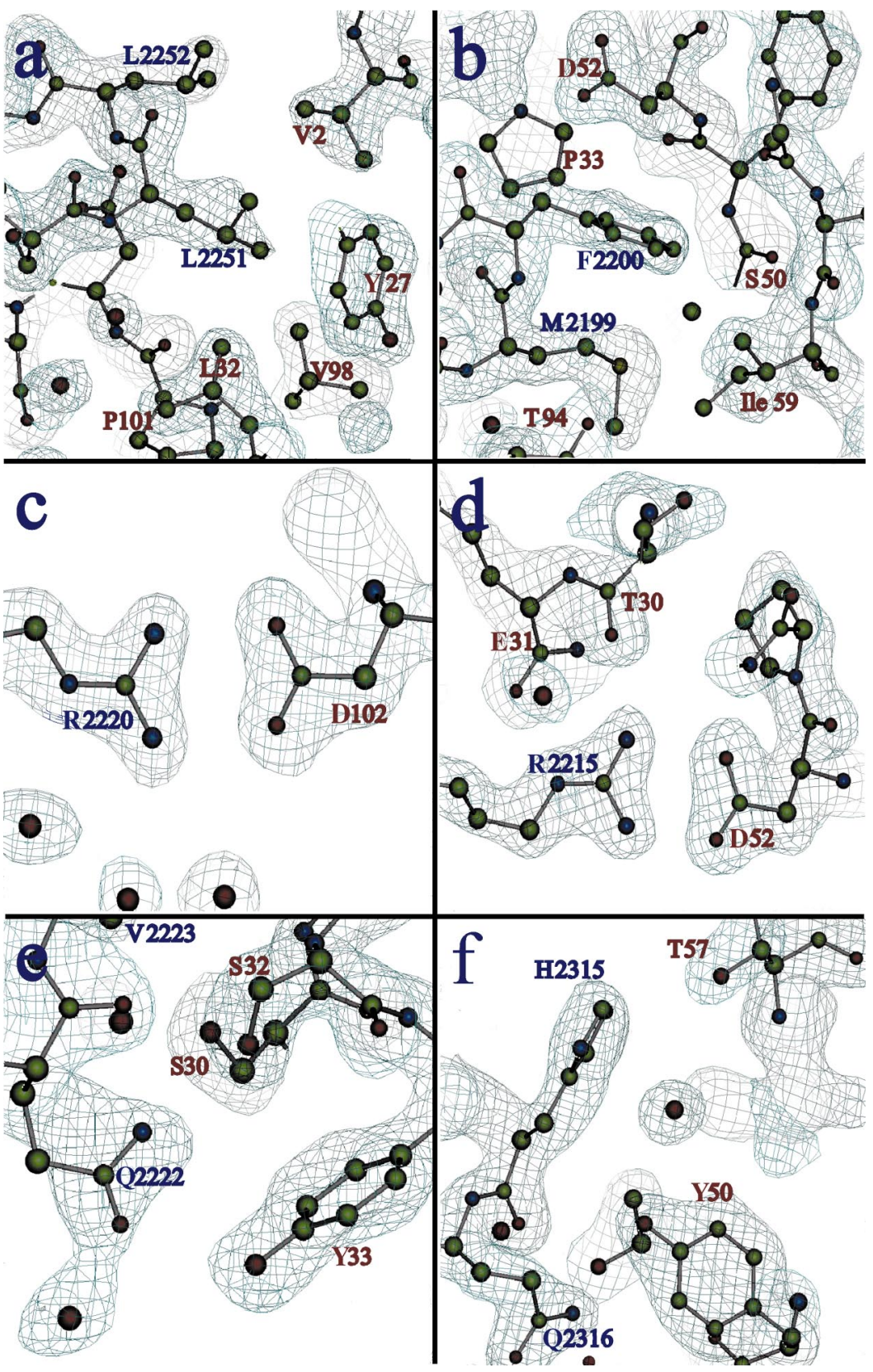

Figure 2. Electron density at residues involved in critical interactions of the binding interface. The first antigenic peptide of C2 (residues 2250 to 2253), corresponding to an exposed hydrophobic $\beta$ turn containing L2251 and 2252, forms primarily hydrophobic interactions with residues from CDR-H1, CDR-H3, and the amino terminus of the heavy chain (A). The second antigenic region from C2 (residues 2197 to 2203), corresponding to a second exposed hydrophobic $\beta$ turn containing M2199 and F2200, exhibits more extensive van der Waals contact with the Fab surface, and there are more polar interactions than in the first epitope (B). Two $\mathrm{R}$ residues from the $\mathrm{C} 2$ domain, both of which are proposed to interact with anionic lipid head groups when factor VIII binds to platelet membranes, form salt links with $D$ residues on the Fab surface. R2220 lies within a cleft between the 2 hydrophobic hairpin turns $(C)$ and interacts with D102 of the heavy chain. R2215 resides on the third loop at this end of the C2 molecule and interacts with D52 of the heavy chain (D). An adjacent loop contains residues Q2222 and V2223, which contact the Fab surface directly (E). V2223 is another hydrophobic residue that was solvent-exposed in the free $\mathrm{C} 2$ structure, and it was proposed that it may make additional contacts with membrane surfaces. Finally, residues H2315 and Q2316 participate in polar interactions with specific residues and buried water molecules at the C2-Fab interface (F). See Table 2 for a list of all contacts in this interface.

time, however, the factor VIII/vWF complex dissociates, and $\mathrm{BO} 2 \mathrm{C} 11$ binds to factor VIII in a nearly irreversible manner. ${ }^{30}$ Indeed, although the association rate constant of $\mathrm{BO} 2 \mathrm{C} 11$ is only 8 -fold lower than that of vWF for factor VIII, the dissociation rate constant of $\mathrm{BO} 2 \mathrm{C} 11$ from factor VIII is 100 -fold lower than that of the vWF-factor VIII complex as estimated by Vlot et al. ${ }^{43}$ Therefore, given the rapid spontaneous dissociation of the factor $\mathrm{VIII} / \mathrm{vWF}$ complex, the protection toward $\mathrm{BO} 2 \mathrm{C} 11$-mediated inactivation provided by vWF is significant only for a short time. ${ }^{44}$ Moreover, $\mathrm{BO} 2 \mathrm{C} 11$ can bind and inactivate factor VIIIa upon its dissociation from $\mathrm{vWF}$, thereby preventing the binding of factor VIIIa to phospholipids. This phenomenon was previously shown to allow rapid inactivation of factor VIII when $\mathrm{BO} 2 \mathrm{C} 11$ was present at concentrations of several hundred Bethesda units. ${ }^{30,44}$ In addition, given the importance of vWF for factor VIII stability in plasma, it is possible that factor VIII bound to $\mathrm{BO} 2 \mathrm{C} 11$ is cleared more rapidly from the circulation..$^{45-47}$ It is noteworthy that polyclonal anti-factor VIII antibodies of the patient from whom the cell line producing $\mathrm{BO} 2 \mathrm{C} 11$ was derived inactivate factor VIII following a type I pattern (M.J., unpublished data, September 1997). This probably occurs because in addition to antibodies toward the $\mathrm{C} 2$ domain, this patient's plasma contains antibodies recognizing antigenic determinants in other regions of the factor VIII molecule, including the heavy chain. ${ }^{48}$

The observed competition between the $\mathrm{BO} 2 \mathrm{C} 11$ antibody and vWF for binding to factor VIII suggests the straightforward explanation that the $\mathrm{C} 2$ domain visualized here either includes or overlaps with the factor VIII binding site for vWF. However, caution must be exercised in proposing structural explanations for the various binding experiments because there are as yet no direct data on the structure of the vWF-factor VIII complex. Two additional hypotheses, which do not exclude the possibility that the C2-domain epitope identified here may overlap the binding site for $\mathrm{vWF}$, can be presented to account for the competition between $\mathrm{BO} 2 \mathrm{C} 11$ and $\mathrm{vWF}$ for binding to factor VIII. The bound $\mathrm{BO} 2 \mathrm{C} 11$ antibody molecule may cause steric interference with the binding of $\mathrm{vWF}$, which is itself an extremely large, multimeric protein. In other words, occlusion of the binding of 2 large proteins may not 
Table 2. Atomic contacts between factor VIII C2 domain and BO2C11

\begin{tabular}{|c|c|c|c|}
\hline C2-domain residue & $\mathrm{BO} 2 \mathrm{C} 11$ residue & Fab chain & Distance $(\AA)$ \\
\hline \multicolumn{4}{|l|}{ Peptide 1} \\
\hline \multirow[t]{2}{*}{ S2250 OG } & D100 OD2 & Heavy & 2.5 \\
\hline & P101 N & Heavy & 3.7 \\
\hline L2251 N & D100 OD2 & Heavy & 3.0 \\
\hline L2251 CG & L32 CD1 & Heavy & 3.4 \\
\hline \multirow[t]{2}{*}{ L2251 CD2 } & Y27 CD2 & Heavy & 3.8 \\
\hline & V2 CG2 & Heavy & 3.5 \\
\hline L2252 CD2 & V2 CG2 & Heavy & 3.7 \\
\hline L2252 N & D100 OD2 & Heavy & 2.7 \\
\hline T2253 N & D100 OD1 & Heavy & 3.4 \\
\hline T2253 CG2 & P101 CD & Heavy & 3.4 \\
\hline \multicolumn{4}{|l|}{ Peptide 2} \\
\hline \multirow[t]{2}{*}{ F2196 CE1 } & S32 OG & Light & 3.6 \\
\hline & Y33 CE1 & Light & 3.5 \\
\hline F2196 CE2 & D102 OD1 & Heavy & 3.4 \\
\hline T2197 OG1 & Y33 OH & Light & 3.4 \\
\hline T2197 O & Y33 ОH & Light & 2.7 \\
\hline N2198 OD1 & D102 O & Heavy & 3.0 \\
\hline N2198 ND2 & G93 O & Light & 3.4 \\
\hline N2198 O & T94 OG1 & Light & 3.6 \\
\hline M2199 N & G93 O & Light & 3.2 \\
\hline M2199 CB & G93 O & Light & 3.1 \\
\hline M2199 CG & T94 O & Light & 3.7 \\
\hline \multirow[t]{3}{*}{ M2199 SD } & 159 CD1 & Heavy & 3.1 \\
\hline & S50 CB & Heavy & 3.4 \\
\hline & H35 CE1 & Heavy & 3.8 \\
\hline F2200 CD1 & P33 CB & Heavy & 3.5 \\
\hline F2200 CD1 & D52 CB & Heavy & 3.7 \\
\hline \multirow[t]{2}{*}{ F2200 CZ } & E57 OE2 & Heavy & 3.4 \\
\hline & 159 CG2 & Heavy & 3.6 \\
\hline \multicolumn{4}{|l|}{ Peptide 3} \\
\hline R2220 NH1 & D102 OD2 & Heavy & 2.9 \\
\hline R2220 NH2 & D102 OD1 & Heavy & 3.0 \\
\hline \multicolumn{4}{|l|}{ Peptide 4} \\
\hline R2215 NE & E31 O & Heavy & 3.0 \\
\hline $\mathrm{R} 2215 \mathrm{NH} 1$ & D52 OD2 & Heavy & 2.8 \\
\hline \multirow[t]{2}{*}{ R2215 NH2 } & D52 OD1 & Heavy & 3.0 \\
\hline & T30 O & Heavy & 2.9 \\
\hline \multicolumn{4}{|l|}{ Peptide 5} \\
\hline Q2222 OE1 & Y33 OH & Light & 3.2 \\
\hline \multirow[t]{2}{*}{ Q2222 NE1 } & S30 OG & Light & 3.6 \\
\hline & S32 OG & Light & 3.2 \\
\hline Q2222 O & S32 OG & Light & 3.3 \\
\hline V2223 CG1 & S30 OG & Light & 3.6 \\
\hline \multicolumn{4}{|l|}{ Peptide 6} \\
\hline H2315 CE1 & T57 OG1 & Light & 3.7 \\
\hline $\mathrm{H} 2315 \mathrm{O}$ & T57 OG1 & Light & 3.5 \\
\hline \multirow[t]{2}{*}{ Q2316 NE2 } & Y50 OH & Light & 3.5 \\
\hline & Y50 CE1 & Light & 3.3 \\
\hline
\end{tabular}

All atoms in the interface from opposing protein molecules displaying contact distances of less than $3.8 \AA$ (corresponding to a conservative estimate of the upper range of distance for van der Waals interactions) are included. The six separate peptides from the factor VIII C2 domain correspond to those forming the observed epitope for BO2C11 binding, as described in "Results" and "Discussion" and illustrated in Figure 2.

involve a direct competition for the same surface on the $\mathrm{C} 2$ domain, but could be due to interference elsewhere between the factor VIII or $\mathrm{vWF}$ proteins. Alternatively, the binding of $\mathrm{BO} 2 \mathrm{C} 11$ to the $\mathrm{C} 2$ domain may prevent a conformational change within factor VIII that is necessary for vWF binding. In support of the first possibility, indirect steric interference between bound $\mathrm{vWF}$ and bound $\mathrm{BO} 2 \mathrm{C} 11$, we note that the binding of vWF involves other regions of factor VIII in addition to the $\mathrm{C} 2$ domain. An acidic stretch of 41 amino acid residues at the amino terminal region of the light chain
(A3-C1-C2) increases the affinity of factor VIII binding to vWF. This peptide is removed during the proteolytic activation of factor VIII. The proximity of this acidic stretch to regions on the C2-domain surface is not yet known.

Several C2-domain missense mutations associated with hemophilia A appear to affect $\mathrm{vWF}$ binding, indicating that these residues may represent part of the vWF-binding surface. However, the effects of these mutations, some of which affect bulky side chains (W2229, R2307, and R2304), on the structure of factor VIII have not yet been characterized. Therefore, it is not yet known whether the substitutions alter merely the surface characteristics of the $\mathrm{C} 2$ domain or whether they result in more profound effects on folding or secretion of the factor VIII protein. The value of these mutations as a tool for mapping the association surface of $\mathrm{C} 2$ with vWF awaits a more complete characterization of the mutations themselves, and it may be possible to investigate this further using recombinant factor VIII constructs. The picture of the C2-domain epitope presented here can now be used to inform additional, detailed mutational and biochemical studies that will test the possible involvement of the epitope region in the binding of vWF to factor VIII.

It is likely that the complex described here is similar to those formed by the $\mathrm{C} 2$ domain with other anti-C2 inhibitor antibodies. The equivalence of the epitope with the proposed membranebinding region is completely consistent with the observed blockage of membrane binding by other anti-C2 inhibitor antibodies. Studies of unrelated antibody complexes have shown that antigenic determinants on protein surfaces may correspond to peptide regions having dynamic flexibility, hydrophobicity, and/or significant solvent accessibility of side chains. ${ }^{49-51}$ The $\mathrm{C} 2$ residues in contact with $\mathrm{BO} 2 \mathrm{C} 11$ meet all of these criteria. Crystal structures of the $\mathrm{C} 2$ domains of factors V and VIII have shown unequivocally that the $\beta$-hairpin turns can assume various orientations under different conditions, ${ }^{11,36}$ and the crystal structures set only a lower limit on the accessible range of motion available to these loops as they interact with various surfaces. The epitope region is also highly hydrophobic and presents a side-chain surface area that is larger than that of other surface loops of similar length on the $\mathrm{C} 2$ domain. The membrane-binding surface of the $\mathrm{C} 2$ domain thus appears to represent an antigenic "hotspot" on the factor VIII surface. A sequence alignment of human and porcine factor VIII supports this conclusion (Figure 5). Chimeric human/porcine factor VIII molecules have been constructed that exhibit less antigenicity against a variety of patient-derived antibody inhibitors. Such chimeric proteins represent a promising approach to improve treatment options for patients who develop inhibitory antibodies. ${ }^{52}$ Inspection
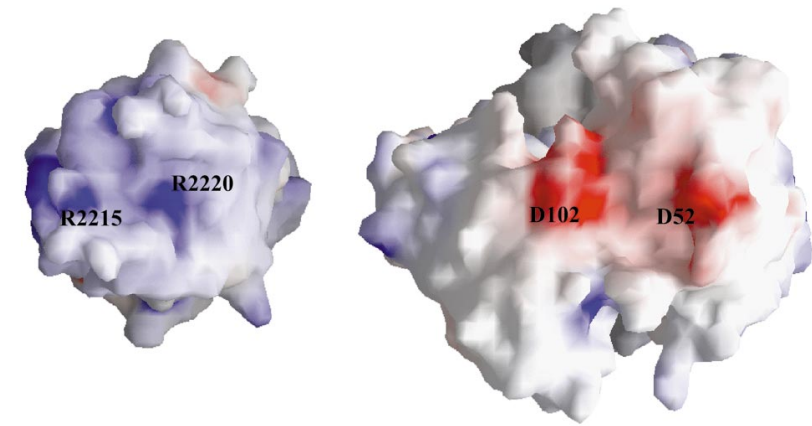

FVIII C2 domain

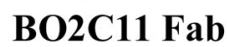

Figure 3. Molecular surface representation of the surfaces that interact in the B02C11-C2-domain complex. The individual proteins have been separated and rotated to allow the reader to view the complementary, buried protein interfaces. The predominantly negative charge (red) of the Fab fragment interacts favorably with the positively charged patches (blue) on the surface of the $\mathrm{C} 2$ domain. 
of the sequence alignment reveals that there are significant differences between the human and porcine sequences at and around the $\beta$-hairpin turn containing M2199 and F2200. Indeed, recent experiments using recombinant factor VIII proteins incorporating point mutations in this region have shown that the substitutions affected the antigenicity of factor VIII against both polyclonal and monoclonal antibodies. These results are consistent with the BO2C11 epitope identified here. ${ }^{53}$

Only 2 point mutations associated with hemophilia A, A2201P and V2223M, have been identified within the antibody interface identified here. The patients carrying these mutations suffered from relatively mild bleeding disorders. ${ }^{10}$ It was proposed previously that the relative dearth of deleterious point mutations near the exposed hydrophobic surface of the $\mathrm{C} 2$ domain reflected a redundant, protective evolution of the membrane-binding region. ${ }^{10,11}$ The binding energy to membrane surfaces was proposed to derive from a combination of favorable solvation changes upon insertion of
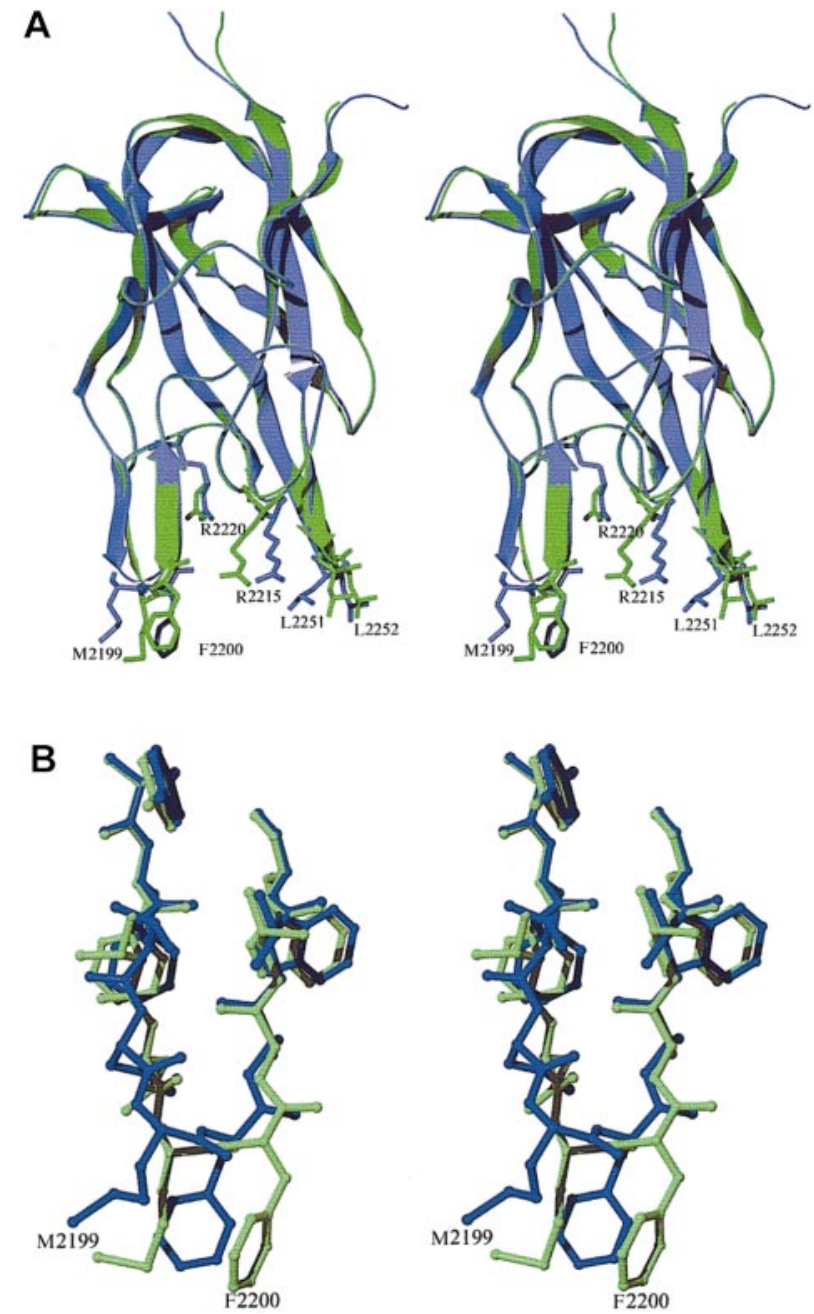

Figure 4. Stereo diagram of superimposed structures of the recombinant factor VIII C2 domain in the free and antibody-bound crystal forms. (A) The free and Fab-complexed C2 proteins are shown in blue and green, respectively. The structure of the $\beta$ core is virtually identical in the 2 structures. Most of the deviations between the structures occur at or near the 2 hydrophobic $\beta$-hairpin turns at the bottom of the figure. The plane formed by the 2 strands of the second $\beta$ hairpin (residues 2197 to 2203) moves to a position perpendicular to that seen in the unbound C2-domain structure. The $\psi$ angle of M2199 rotates from $-11^{\circ}$ to $+122^{\circ}$, whereas in F2200, the $\phi$ and $\psi$ angles rotate from $-99^{\circ}$ to $+56^{\circ}$ and from $-23^{\circ}$ to $+26^{\circ}$, respectively. This region interacts with residues in $\mathrm{CDR}-\mathrm{H} 1, \mathrm{CDR}-\mathrm{H} 2$, and $\mathrm{CDR}-\mathrm{H} 3$ of the heavy chain as well as with sites on CDR-L1 and CDR-L3 of the light chain. (B) Rotations about backbone dihedral angles in the $\beta$ hairpin containing residues N2198 through A2201 shift the orientation of these side chains by up to $5 \AA$.

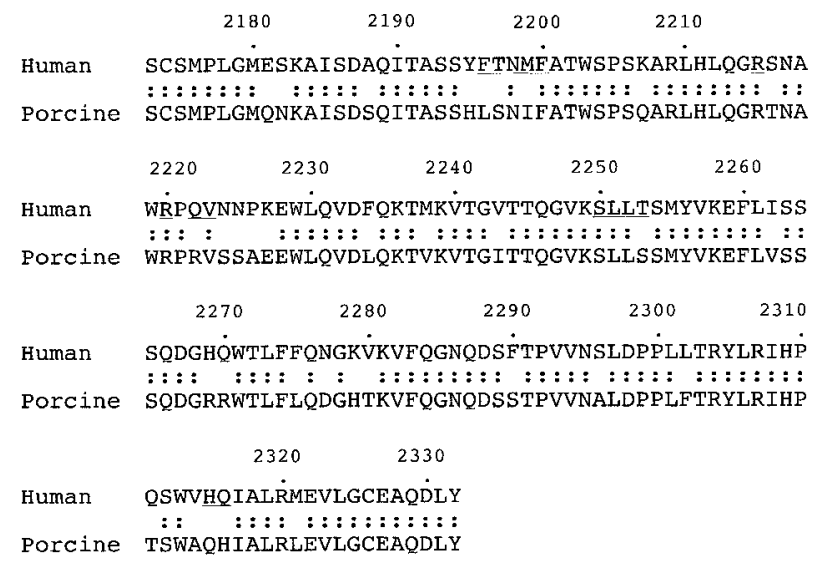

Figure 5. Sequence alignment of the $\mathbf{C 2}$ domains of human and porcine factor VIII. The regions corresponding to those in the $\mathrm{C} 2$-domain epitope in contact with the $\mathrm{BO} 2 \mathrm{C} 11 \mathrm{Fab}$ are underlined.

hydrophobic residues into a nonpolar lipid environment. Favorable electrostatic interactions were also proposed between several basic residues and polar phospholipid head groups. At least 10 to 12 amino acid side chains were deemed likely to contribute to the interface with the membrane. Because the free energy of solvation changes involving hydrophobic moieties is relatively insensitive to precise side-chain orientation, the attachment of the $\mathrm{C} 2$ domain to membranes should readily accommodate minor structural changes due to movement of the loops or substitutions of individual side chains. Similarly, the large number of residues involved in the membrane-protein interface would tend to minimize the energetic penalty of mutating any individual side chain in this region. In contrast, the binding of this $\mathrm{C} 2$ surface to protein ligands, including vWF or inhibitor antibodies, may be more vulnerable to conformational changes and to disruptions caused by point mutations. This may have positive implications for patients with hemophilia A with an antibody inhibitor response. It should be possible to introduce minor modifications to these loops that preclude an effective antibody/antigen interaction but that result in a molecule that is still competent to bind membranes and to carry out the critical cofactor function of factor VIII in coagulation. It is well established that effective hemostasis is possible even with a plasma concentration of factor VIII as low as $10 \%$ of average levels. Below this level, an increase in factor VIII concentration of even a few percentage points can have a profound impact on the quality of life for the patient. Thus, the design of a "hobbled" factor VIII, which may sacrifice some membrane-binding capacity to decrease the antigenicity of the infusion, may be a desirable and achievable goal. The identification here of specific amino acid residues mediating an inhibitor antibody response presents a compelling opportunity to further fine tune the production of improved, recombinant "designer" factor VIII proteins that are tolerated by a larger fraction of the patient population.

\section{Acknowledgments}

We thank Betty W. Shen for assistance at all stages of structure determination; Eric Galburt, Roland Strong, Kam Zhang, and Adrian Ferre-D'Amare for advice and discussion; Earl Davie and Kazuo Fujikawa for assistance with the C2-domain purification and analysis; Benoît Desqueper for production of BO2C11 Fab fragment; and Thomas Earnest and staff at ALS beamline 5.0.2 for assistance with data collection. 


\section{References}

1. Fay PJ. Regulation of factor VIIla in the intrinsic factor Xase. Thromb Haemost. 1999;82:193-200.

2. Kane WH, Davie EW. Blood coagulation factors $\mathrm{V}$ and VIII: structural and functional similarities and their relationship to hemorrhagic and thrombotic disorders. Blood. 1988;71:539-555.

3. Lenting PJ, van Mourik JA, Mertens K. The life cycle of coagulation factor VIII in view of its structure and function. Blood. 1998;92:3983-3996.

4. Saenko EL, Scandella D. A mechanism for inhibition of factor VIII binding to phospholipid by von Willebrand factor. J Biol Chem. 1995;270:1382613833.

5. Toole JJ, Knopf JL, Wozney JM, et al. Molecular cloning of a cDNA encoding human antihaemophilic factor. Nature. 1984;312:342-347.

6. Vehar GA, Keyt B, Eaton D, et al. Structure of human factor VIII. Nature. 1984;312:337-342.

7. Baumgartner S, Hofmann K, Chiquet-Ehrismann $\mathrm{R}$, Bucher $\mathrm{P}$. The discoidin domain family revisited: new members from prokaryotes and a homology-based fold prediction. Protein Sci. 1998; 7:1626-1631

8. Pellequer JL, Gale AJ, Griffin JH, Getzoff ED. Homology models of the $C$ domains of blood coagulation factors $\mathrm{V}$ and VIII: a proposed membrane binding mode for FV and FVIII C2 domains. Blood Cells Mol Dis. 1998:24:448-461.

9. Gilbert GE, Drinkwater D. Specific membrane binding of factor VIII is mediated by O-phosphoL-serine, a moiety of phosphatidylserine. Biochemistry. 1993;32:9577-9585.

10. Liu ML, Shen BW, Nakaya S, et al. Hemophilic factor VIII C1- and C2-domain missense mutations and their modeling to the 1.5-angstrom human C2-domain crystal structure. Blood. 2000; 96:979-987

11. Pratt KP, Shen BW, Takeshima K, Davie EW, Fujikawa K, Stoddard BL. Structure of the C2 domain of human factor VIII at $1.5 \mathrm{~A}$ resolution. Nature. 1999;402:439-442.

12. Antonarakis SE, Rossiter JP, Young M, et al. Factor VIII gene inversions in severe hemophilia A: results of an international consortium study. Blood. 1995;86:2206-2212.

13. McMillan CW, Shapiro SS, Whitehurst D, Hoyer LW, Rao AV, Lazerson J. The natural history of factor VIII:C inhibitors in patients with hemophilia A: a national cooperative study, II: observations on the initial development of factor VIII:C inhibitors. Blood. 1988;71:344-348.

14. Rizza CR, Biggs $R$. The treatment of patients who have factor-VIII antibodies. Br J Haematol. 1973; 24:65-82

15. Schwaab R, Brackmann HH, Meyer C, et al. Haemophilia A: mutation type determines risk of inhibitor formation. Thromb Haemost. 1995;74: 1402-1406.

16. Tuddenham EG, Schwaab R, Seehafer J, et al. Haemophilia A: database of nucleotide substitutions, deletions, insertions and rearrangements of the factor VIII gene, second edition [corrected and republished article originally printed in Nucleic Acids Res. 1994:22:3511-3533]. Nucleic Acids Res. 1994;22:4851-4868.

17. Hay CR. Factor VIII inhibitors in mild and moderate-severity haemophilia A. Haemophilia. 1998;4: 558-563.

18. Hay CR, Ludlam CA, Colvin BT, et al. Factor VIII inhibitors in mild and moderate-severity haemophilia A: UK Haemophilia Centre Directors Organisation [see comments]. Thromb Haemost. 1998;79:762-766.

19. Bossi P, Cabane J, Ninet J, et al. Acquired hemophilia due to factor VIII inhibitors in 34 patients. Am J Med. 1998;105:400-408.
20. Hoyer LW, Scandella D. Factor VIII inhibitors: structure and function in autoantibody and hemophilia A patients. Semin Hematol. 1994;31:1-5.

21. Gilles JG, Lavend'homme R, Peerlinck K, et al. Some factor VIII (FVIII) inhibitors recognise a FVIII epitope(s) that is present only on FVIII-vWF complexes. Thromb Haemost. 1999;82:40-45.

22. Healey JF, Barrow RT, Tamim HM, et al. Residues Glu2181-Val2243 contain a major determinant of the inhibitory epitope in the $\mathrm{C} 2$ domain of human factor VIII. Blood. 1998;92:3701-3709.

23. Kuwabara I, Maruyama H, Kamisue S, Shima M, Yoshioka A, Maruyama IN. Mapping of the minimal domain encoding a conformational epitope by lambda phage surface display: factor VIII inhibitor antibodies from haemophilia A patients. J Immunol Methods. 1999;224:89-99.

24. Laub R, Di Giambattista M, Fondu P, et al. Inhibitors in German hemophilia A patients treated with a double virus inactivated factor VIII concentrate bind to the C2 domain of FVIII light chain. Thromb Haemost. 1999;81:39-44.

25. Nogami K, Shima M, Nakai $H$, et al. Identification of a factor VIII peptide, residues 2315-2330, which neutralizes human factor VIII C2 inhibitor alloantibodies: requirement of Cys2326 and Glu2327 for maximum effect. Br J Haematol. 1999;107:196-203.

26. Shima M, Scandella D, Yoshioka A, et al. A factor VIII neutralizing monoclonal antibody and a human inhibitor alloantibody recognizing epitopes in the C2 domain inhibit factor VIII binding to von Willebrand factor and to phosphatidylserine. Thromb Haemost. 1993;69:240-246.

27. Jacquemin M, Benhida A, Peerlinck K, et al. A human antibody directed to the factor VIII C1 domain inhibits factor VIII cofactor activity and binding to von Willebrand factor. Blood. 2000;95:156163.

28. Zhong D, Saenko EL, Shima M, Felch M, Scandella D. Some human inhibitor antibodies interfere with factor VIII binding to factor IX. Blood. 1998:92:136-142.

29. Scandella D, Gilbert GE, Shima M, et al. Some factor VIII inhibitor antibodies recognize a common epitope corresponding to $\mathrm{C} 2$ domain amino acids 2248 through 2312, which overlap a phospholipid-binding site. Blood. 1995;86:1811-1819.

30. Jacquemin MG, Desqueper BG, Benhida A, et al. Mechanism and kinetics of factor VIII inactivation: study with an IgG4 monoclonal antibody derived from a hemophilia A patient with inhibitor. Blood. 1998;92:496-506.

31. Otwinowski ZM, W. Processing of X-ray diffraction data collected in oscillation mode. Methods Enzymol. 1997;276:307-326.

32. Kissinger CR, Gehlhaar DK, Fogel DB. Rapid automated molecular replacement by evolutionary search. Acta Crystallogr D Biol Crystallogr. 1999; 55:484-491

33. McRee DE. XtalView/Xfit-a versatile program for manipulating atomic coordinates and electron density. J Struct Biol. 1999;125:156-165.

34. Brunger AT, Adams PD, Clore GM, et al. Crystallography \& NMR system: a new software suite for macromolecular structure determination. Acta Crystallogr D Biol Crystallogr. 1998;54:905-921.

35. Laskowski RJ, Macarthur MW, Moss DS, Thornton JM. PROCHECK: a program to check the stereochemical quality of protein structures. J Appl Crystallogr. 1993;26:283-290.

36. Macedo-Ribeiro S, Bode W, Huber R, et al. Crystal structures of the membrane-binding $\mathrm{C} 2$ domain of human coagulation factor $\mathrm{V}$. Nature. 1999;402:434-439.

37. Biggs R, Austen DE, Denson KW, Borrett R,
Rizza CR. The mode of action of antibodies which destroy factor VIII, II: antibodies which give complex concentration graphs. Br J Haematol. 1972;23:137-155.

38. Biggs R, Austen DE, Denson KW, Rizza CR, Borrett $R$. The mode of action of antibodies which destroy factor VIII, I: antibodies which have second-order concentration graphs. Br J Haematol. 1972;23:125-135.

39. Gawryl MS, Hoyer LW. Inactivation of factor VIII coagulant activity by two different types of human antibodies. Blood. 1982:60:1103-1109.

40. Biggs R. Antibodies to factor VIII clotting activity (VIII:C). In: Biggs R, Rizza CR, eds. Human Blood Coagulation, Haemostasis and Thrombosis. 3rd ed. Oxford, England: Blackwell Scientific Publications; 1984:310-332.

41. Verbruggen B, Novakova I, Wessels H, Boezeman J, van den Berg M, Mauser-Bunschoten E. The Nijmegen modification of the Bethesda assay for factor VIII:C inhibitors: improved specificity and reliability. Thromb Haemost. 1995;73:247251.

42. Peerlinck K, Jacquemin MG, Arnout J, et al. Antifactor VIII antibody inhibiting allogeneic but not autologous factor VIII in patients with mild hemophilia A. Blood. 1999;93:2267-2273.

43. Vlot AJ, Koppelman SJ, Meijers JC, et al. Kinetics of factor VIII-von Willebrand factor association. Blood. 1996;87:1809-1816.

44. Jacquemin M, Desqueper B, Benhida A, et al. von Willebrand factor-dependent protection of factor VIII from inactivation by inhibitory antibody: study with a human monoclonal antibody [abstract]. Haemophilia. 2000;6:220.

45. Saenko EL, Yakhyaev AV, Mikhailenko I, Strickland DK, Sarafanov AG. Role of the low density lipoprotein-related protein receptor in mediation of factor VIII catabolism. J Biol Chem. 1999;274: 37685-37692

46. Schwartz HP, Lenting PJ, Binder B, et al. Involvement of low-density lipoprotein receptor-related protein (LRP) in the clearance of factor VIII in von Willebrand factor-deficient mice. Blood. 2000;95: 1703-1708.

47. Weiss HJ, Sussman II, Hoyer LW. Stabilization of factor VIII in plasma by the von Willebrand factor: studies on posttransfusion and dissociated factor VIII and in patients with von Willebrand's disease. J Clin Invest. 1977;60:390-404.

48. Gilles JG, Arnout J, Vermylen J, Saint-Remy JM. Anti-factor VIII antibodies of hemophiliac patients are frequently directed towards nonfunctional determinants and do not exhibit isotypic restriction. Blood. 1993;82:2452-2461.

49. Barrow RT, Healey JF, Gailani D, Scandella D, Lollar P. Reduction of the antigenicity of factor VIII toward complex inhibitory antibody plasmas using multiply-substituted hybrid human/porcine factor VIII molecules. Blood. 2000;95:564-568.

50. Berzofsky JA. Intrinsic and extrinsic factors in protein antigenic structure. Science. 1985;229: 932-940.

51. Westhof E, Altschuh D, Moras D, et al. Correlation between segmental mobility and the location of antigenic determinants in proteins. Nature. 1984;311:123-126.

52. Lollar P, Knutson GJ, Fass DN. Activation of porcine factor VIII:C by thrombin and factor $\mathrm{Xa}$. Biochemistry. 1985;24:8056-8064.

53. Barrow RT, Healey JF, Jacquemin MG, SaintRemy JM, Lollar P. Antigenicity of putative phospholipid membrane-binding residues in factor VIII. Blood. 2001;97:169-174. 